\title{
Correction to: Pressure Sensor Based on Quantum Well-Structured Photonic Crystal
}

\author{
Bhuvneshwer Suthar ${ }^{1} \cdot$ Anami Bhargava ${ }^{2}$
}

Received: 20 July 2020 / Published online: 10 October 2020

(C) Springer Nature B.V. 2020

\section{Correction to: Silicon}

https://doi.org/10.1007/s12633-020-00552-9

In the article, the corrections in citation of references are as follow:

In section 2 on page 1 , citation [11,13] should read as [11, 12] In section 3 , on page 2 , citation $[10,14]$ should read as $[10,13]$ In section 4 , on page 2 , citation $[15,16]$ should read as $[14,15]$ In section 4, on page 3 , citation [17] should read as [16] In section 4 , on page 3 , citation $[18,19]$ should read as $[17,18]$ In section 4 , on page 4 , citation $[20,21]$ should read as $[19,20]$ In section 4 , on page 4 , citation $[8,21,21]$ should read as $[8,20,21]$

Publisher's Note Springer Nature remains neutral with regard to jurisdictional claims in published maps and institutional affiliations.

The online version of the original article can be found at https://doi.org/ 10.1007/s12633-020-00552-9

Bhuvneshwer Suthar

bhuvneshwer@gmail.com

Anami Bhargava

anamib6@gmail.com

1 Department of Physics, M.L.B. Government College, Nokha, Rajasthan 334803, India

2 Department of Physics, Government Dungar College, Bikaner, Rajasthan 334001, India 